\title{
Editorial
}

\section{New Roles of Advanced Industrial Engineering}

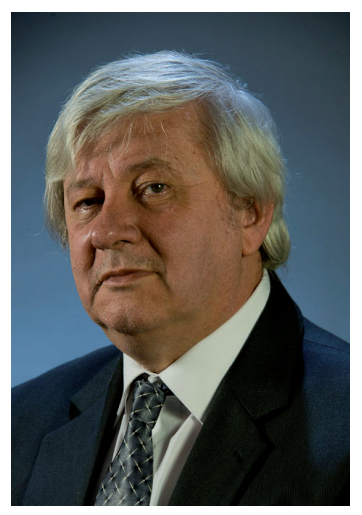

\author{
prof. Ing. Jozef Kováč, CSc. \\ Technical University of Košice, Faculty of Mechanical Engineering, Institute of Management \\ prof. Ing. Jozef Kováč, CSc, is professor an also a head of Institute of Management, Industrial and Digital \\ Engineering. His professional activities are oriented on the analysis and development of new methods and \\ practices of integrated design of production systems and testing of design solutions.
}

Classical industrial engineering due to the necessity for rapid changes in the industry has significant deficits. Advanced Industrial Engineering overcomes these deficits by applying methods, procedures and tools of digital and virtual technology, Outputs are presented by models of digital plants and enterprises. New innovative processes for designing and implementing of production processes and systems for plants and businesses of the future are the part of industry-specific challenges such as Industry 4.0, Smart Factory, RAMI, etc.

Through digital models in a virtual environment, changes in business processes and systems can't only be modelled, studied, and simulated, but almost risk-free optimized. Simulation and modelling integrate knowledge in systems and contribute to increasing the level of their technical intelligence. Modelling, simulation verification and optimization of business processes and systems are now realized with the support of advanced CAx software products.

In the plants of the future the realized processes have integrated digital support. They are trough digital technologies and technical mediums integrated throughout the value chain. The virtual world is coupled with the real production through a continuous data flow, from the design and usage of the product, through service, recycling disassembly, and vice versa. The digital enterprise can compactly allow to solve all mixed necessities across the value chain of all types of products and productions.

The role of industrial engineering is to select and use properly the methods that most contribute to the achievement of goals that have enterprise. Advanced industrial engineering through its development will be:

- Strengthen the ability of enterprises to react to market changes, create conditions and design solutions that lead to the realization of tasks and production optimization.

- Apply methods for identification of vulnerable locations in the production and value chain oriented on the production life cycle.

- Use methods obtained from the realistic scenarios of new products, technologies, production systems, etc. realization).

- Exploit the potential of digital and virtual technologies, methods, procedures and tools to support engineering activities. 